ORIGINAL ARTICLE

\title{
High cystine in platelets from patients with nephropathic cystinosis: a chemical, ultrastructural, and functional evaluation
}

\author{
L Olcay, E Erdemli, M Kesimer, Y Büyükașık, H Okur, H S Kalkanoğlu, T Coșkun, C Altay
}

J Clin Pathol 2005;58:939-945. doi: 10.1136/icp.2005.027177

See end of article for authors' affiliations

.....................

Correspondence to: Dr L Olcay, Sağlik 1 Sok. No:10/10, 06410

Sihhıye, Ankara, Turkey; laleolcay@hotmail.com

Accepted for publication 26 February 2005
Aim: To investigate the morphology and function of platelets in nephropathic cystinosis (NC). Methods: Seven patients (mean age, 6.5 years; SD, 20 months) with NC were investigated. Their platelets were examined by transmission electron microscopy (TEM) and the characteristics of the dense granules (DGs) were determined by mepacrine labelling and the uranaffin reaction. Bleeding time, turbidometric aggregation, and luminescence aggregation were studied and intraplatelet cystine was measured.

Results: Increased intraplatelet cystine, primary and secondary aggregation defects, and the absence of ATP release were demonstrated. TEM revealed DGs of various shapes and sizes and lamellary or amorphous cytoplasmic inclusions. Viscous material had been released into the vacuolar spaces and enlarged open canalicular system. Mepacrine labelling revealed that the numbers of DGs/platelet were comparable between the patients and the controls (mean, $2.9(S D, 0.22) v 3.32(0.18) ; p=0.34)$. The uranaffin reaction revealed that the numbers of type 1,3, and 4 DGs were comparable between the patients and the controls, but that there were fewer type 2 DGs in the patients (mean, 8.5 (SD, 1.95) $v$ 17.22 (1.58); $p=0.01$ ). TEM for platelet aggregation revealed a lack of induction and/or defective execution and/or delayed transmission. The patients' intraplatelet cystine concentrations were higher than the controls (mean, $1.56(\mathrm{SD}, 0.84) \vee 0.08(0.01) \mathrm{nmol} / \mathrm{mg}$ protein; $\mathrm{p}=0.009)$.

Conclusions: This is the first report to demonstrate raised intraplatelet cystine, abnormal platelet ultrastructural findings, and defective aggregation in NC.
$\mathrm{C}$ stinosis is a disorder with autosomal recessive transmission caused by defective carrier mediated transport of the amino acid cystine across the lysosomal membrane. ${ }^{1}$ In the "nephropathic" form of the disease, children develop renal Fanconi syndrome, usually at around 6-12 months of age, and then hypothyroidism, photophobia, chronic renal failure, myopathy, difficulty in swallowing, retinal blindness, diabetes mellitus, male hypogonadism, pulmonary dysfunction, and central nervous system dysfunction. ${ }^{12}$

\footnotetext{
"Cystinosis is a disorder with autosomal recessive transmission caused by defective carrier mediated transport of the amino acid cystine across the lysosomal membrane"
}

Although functional abnormalities of various organs associated with this disorder have been well defined, platelets have not been studied before. Upon observation of prolonged bleeding at the venipuncture sites in a child with nephropathic cystinosis (NC), we planned to evaluate the functions and electron microscopic features of platelets from this patient along with other patients previously diagnosed with NC.

\section{METHODS \\ Patients}

All of the patients $(\mathrm{n}=7$; mean age, 6.5 years; SD, 20 months; six male; one female) with the diagnosis of NC were followed up at the division of nutrition and metabolism, Hacettepe University, Ankara, Turkey. They were diagnosed at 12-21 months of age. Parents were first or second degree relatives in five of the seven families. Two patients were siblings (patients 6 and 7). All of the patients met the criteria for NC. Table 1 provides some of the patients' laboratory and clinical features. At the time of evaluation, only two patients, who had chronic renal failure (CRF), complained of prolonged bleeding from cuts or venipuncture sites and easy bruising (patients 1 and 6). All had been taking cysteamine, Joule and Scholl solutions, and vitamin D3. The bicarbonate value was normal in all of the patients and renal function tests were normal at the time of evaluation except for the two patients with CRF (patients 1 and 6). Patients 6 and 7 were lost to follow up during our study, so that tests other than platelet aggregation could be performed for patients $1-5$ only. An ATP release study could be performed in three patients only. The control group was made up of five healthy subjects.

\section{Transmission electron microscopy (TEM)}

Venous blood drawn from the patients was mixed with acid citrate dextrose anticoagulant in a 6 to 1 ratio and platelet rich plasma (PRP) was prepared by centrifugation at $150 \times \mathrm{g}$ for 20 minutes at room temperature. After fixation in 3\% gluteraldehyde in phosphate buffer, platelets were washed with phosphate buffer. Postfixation with $1 \%$ osmium tetroxide was performed and the specimens were dehydrated in a graded series of alcohol and embedded in araldite. Ultrathin serial sections were cut on a Leica Ultracut R ultramicrotome (Leica, Vienna, Austria), stained with uranyl acetate and lead citrate, and examined by a Leo 906 E TEM. $^{3}$

Abbreviations: CRF, chronic renal failure; DG, dense granule; NC, nephropathic cystinosis; PPP, platelet poor plasma; PRP, platelet rich plasma; $\delta$-SPD, delta storage pool disease; TEM, transmission electron microscopy 
Table 1 Laboratory and clinical features of the patients

\begin{tabular}{|c|c|c|c|c|c|c|c|c|c|c|c|c|}
\hline Patient & Age/Sex & $\begin{array}{l}\text { Bleeding } \\
\text { symptoms }\end{array}$ & $\begin{array}{l}\text { Associated } \\
\text { disorders }\end{array}$ & $\begin{array}{l}\text { Platelet } \\
\left(\times 10^{9} / \mathrm{I}\right)\end{array}$ & $\begin{array}{l}\text { Bleeding } \\
\text { time }\end{array}$ & Ristocetin & ADP $(2 \mu M)$ & ADP $(10 \mu M)$ & $\begin{array}{l}\text { Collagen } \\
(2 \mu \mathrm{M})\end{array}$ & $\begin{array}{l}\text { Epinephrine } \\
(10 \mu \mathrm{M})\end{array}$ & $\begin{array}{l}\text { ATP } \\
\text { release } \\
(2 \mu \mathrm{M} \\
\text { ADP) }\end{array}$ & $\begin{array}{l}\text { ATP release } \\
(10 \mu \mathrm{M} \text { ADP })\end{array}$ \\
\hline 1 & $7 y / M$ & Present & $\begin{array}{l}\text { CRF, EPO } \\
\text { responsive } \\
\text { anaemia, } \\
\text { hepatomegaly }\end{array}$ & 236 & $19 \min$ & $\mathrm{N}$ & $\begin{array}{l}\text { Reduced } \\
\text { primary } \\
\text { aggregation }\end{array}$ & $\begin{array}{l}\text { Minimal } \\
\text { improvement }\end{array}$ & $\begin{array}{l}\text { Reduced } \\
\text { primary } \\
\text { aggregation }\end{array}$ & $\begin{array}{l}\text { Reduced } \\
\text { primary } \\
\text { aggregation }\end{array}$ & Absent & Minimal \\
\hline 2 & 1 y $6 \mathrm{~m} / \mathrm{M}$ & Absent & None & 406 & $9 \min$ & $\mathrm{N}$ & $\begin{array}{l}\text { Absent } \\
\text { secondary } \\
\text { aggregation }\end{array}$ & $N$ & $\mathrm{~N}$ & $N$ & $N^{*}$ & ND* \\
\hline 3 & $1 \mathrm{y} / \mathrm{F}$ & Absent & None & 217 & $25 \mathrm{~min}$ & $\mathrm{~N}$ & $\begin{array}{l}\text { Absent } \\
\text { secondary } \\
\text { aggregation }\end{array}$ & $\begin{array}{l}\text { Minimal } \\
\text { improvement }\end{array}$ & $\mathrm{N}$ & $\begin{array}{l}\text { Reduced } \\
\text { secondary } \\
\text { aggregation }\end{array}$ & Absent & Minimal \\
\hline 4 & $3 y 6 \mathrm{~m} / \mathrm{M}$ & Absent & None & 510 & $9 \min 30 s$ & $\mathrm{~N}$ & $\mathrm{~N}$ & $\mathrm{~N}$ & $\mathrm{~N}$ & $\mathrm{~N}$ & $\mathrm{~N}$ & $\mathrm{~N}$ \\
\hline 5 & $2 y 6 \mathrm{~m} / \mathrm{M}$ & Absent & None & 232 & $15 \min 7 \mathrm{~s}$ & $\mathrm{~N}$ & $\begin{array}{l}\text { Absent } \\
\text { secondary } \\
\text { aggregation }\end{array}$ & $\begin{array}{l}\text { Minimal } \\
\text { improvement }\end{array}$ & $\mathrm{N}$ & $\begin{array}{l}\text { Absent } \\
\text { secondary } \\
\text { aggregation }\end{array}$ & ND & ND \\
\hline 6 & $9 y 8 \mathrm{~m} / \mathrm{M}$ & Present & CRF & 257 & $21 \mathrm{~min}$ & $\mathrm{~N}$ & $\begin{array}{l}\text { Absent } \\
\text { secondary } \\
\text { aggregation }\end{array}$ & ND & $\mathrm{N}$ & $\mathrm{ND}^{*}$ & $N D^{*}$ & ND* \\
\hline 7 & $5 y 9 \mathrm{~m} / \mathrm{M}$ & Absent & None & 300 & $4 \min 30 \mathrm{~s}$ & $\mathrm{~N}$ & $\mathrm{~N}$ & $\mathrm{~N}$ & $\mathrm{~N}$ & $N^{*}$ & $N^{*}$ & $N^{*}$ \\
\hline
\end{tabular}

\section{Mepacrine labelling of the dense granules}

Blood was collected in a plastic tube containing ACD solution. PRP was prepared by centrifugation at $100 \times g$ for 10 minutes at $14^{\circ} \mathrm{C}$. Mepacrine $(1 \mu \mathrm{M}$; Sigma, St Louis, Missouri, USA) was added to $1 \mathrm{ml}$ of PRP and the solution was incubated for 20 minutes at $37^{\circ} \mathrm{C}^{4{ }^{5}}$ Samples were then resuspended in buffer ( $130 \mathrm{mmol} \mathrm{NaCl}, 5 \mathrm{mmol} \mathrm{KCl}, 1 \mathrm{mmol}$ $\mathrm{NaH}_{2} \mathrm{PO}_{4}, 24 \mathrm{mmol} \mathrm{NaHCO}_{3}, 2$ mmol EDTA Na 2,10 mmol glucose, and $12.5 \mathrm{mmol}$ saccharose, $\mathrm{pH} 7.4$ ) to a final platelet concentration of $400 \times 10^{9}$ /litre. A drop of this suspension was placed on a slide and a coverslip was applied. The greenish yellow fluorescent dense granules (DGs) were visualised under a fluorescent microscope (Zeiss Axoscope; Zeiss, Thornwood, New York, USA). The DGs were counted in 84-106 platelets for each sample. The results were presented as the mean DG number/platelet.

\section{Uranaffin reaction on thin section electron microscopy} The patients' gluteraldehyde fixed platelets were washed for five minutes, resuspended, and centrifuged three times in $0.9 \% \mathrm{NaCl}$. After the third wash, the platelets were combined with 4\% uranyl acetate in distilled water at $\mathrm{pH} 3.9$. Incubation was continued at $4^{\circ} \mathrm{C}$ for $24-48$ hours. The treated samples were washed twice for five minutes each with distilled water, centrifuged to form pellets, and combined with $2 \%$ osmic acid in $0.2 \mathrm{~mol} /$ litre cacodylate buffer for 90 minutes at $4^{\circ} \mathrm{C}$. The samples were then dehydrated in alcohols and embedded in Ara Idit CY 212. ${ }^{3}$ The uronaffin stained platelets were classified depending on the nature of their electron dense core materials according to Weiss and colleagues $^{3}$ as follows: type 1, containing solid cores occupying more than $50 \%$ of the granule interior; type 2, containing solid cores occupying less than $50 \%$ of the granule interior; type 3, containing fragmented cores; and type 4, containing no visible cores.

\section{Examination of platelet function}

Bleeding time was measured by the modified Ivy method using a "template device" (Simplate R; Organon Teknika GmbH, Eppelheim, Germany). The patients were instructed to avoid aspirin and non-steroidal anti-inflammatory drugs for 10 days before bleeding time and platelet aggregation testing.

Turbidometric and luminescence aggregation tests were carried out on a Chrono-log $560 \mathrm{Ca}$ aggregometer, with minor modifications of the methods described previously. ${ }^{6}$ Blood samples were collected with minimum trauma in 3.8\% trisodium citrate ( $1 / 9$ dilution) containing tubes. All studies were performed within two hours of blood collection. PRP and platelet poor plasma (PPP) were obtained by centrifuging the anticoagulated blood samples for 10 minutes at $700 \times g$ and for 15 minutes at $5000 \times g$, respectively. For turbidometric tests, PRP and PPP samples were placed into siliconised aggregation cuvettes with a reusable stir bar in $500 \mathrm{ml}$ aliquots. After five minutes, $100 \%$ and $0 \%$ baselines were set and reagent induced aggregation was observed after a further five minutes in $1000 \times g$ stirred samples. Platelet aggregation was studied with collagen $(2 \mathrm{mg} / \mathrm{ml})$, ristocetin $(1.25 \mathrm{mg} / \mathrm{ml})$, and two different concentrations of ADP $(2 \mu \mathrm{M}$ and $10 \mu \mathrm{M})$. For lumiaggregometry, $450 \mathrm{ml}$ PRP and $50 \mathrm{ml}$ luciferin-luciferase were placed into a siliconised aggregation cuvette with a reusable stir bar. After five minutes, platelet aggregation was induced with $2 \mu \mathrm{M}$ and $10 \mu \mathrm{M}$ ADP and the amount of ATP released was calculated by means of a control luminescence spike induced by a $2 \mu \mathrm{M}$ ATP standard. The tests were repeated at least twice. Aggregation studies were performed at $37^{\circ} \mathrm{C}$.

\section{TEM evaluation of platelet aggregation}

PRP was obtained as described above. After the addition of $2 \mu \mathrm{M}$ ADP, samples were removed at the second, eighth, and 14th minutes for both the patients and the controls and were prepared for TEM.

\section{Determination of intraplatelet cystine concentrations}

When determining intraplatelet cystine values, we also evaluated the concentration of cystine in leucocytes as a comparison. Blood cell isolation and determination of the intraplatelet and leucocyte cystine concentrations were performed according to the white cell cystine group protocols reported previously. ${ }^{78}$ Fresh blood samples were taken from five patients and five healthy children, directly into an acid/ citrate/dextrose anticoagulant. Platelets and leucocytes were isolated from blood samples using Histopaque ${ }^{\circledR}$ (Sigma, Poole, Dorset, UK), which contains polysucrose (60 g/litre) and has a $1.119 \mathrm{~g} / \mathrm{ml}$ density, as the separating medium. At least $10 \mathrm{ml}$ of blood was slowly overlayed on to $3.5 \mathrm{ml}$ of Histopaque in a $15 \mathrm{ml}$ test tube. All steps were performed at $4^{\circ} \mathrm{C}$ unless stated otherwise. Centrifugation was performed at $350 \times \mathrm{g}$ for 15 minutes at $20^{\circ} \mathrm{C}$. PRP was carefully removed from the top and transferred into $3 \mathrm{ml}$ polycarbonate centrifuge tubes. The next layer, which contained the 


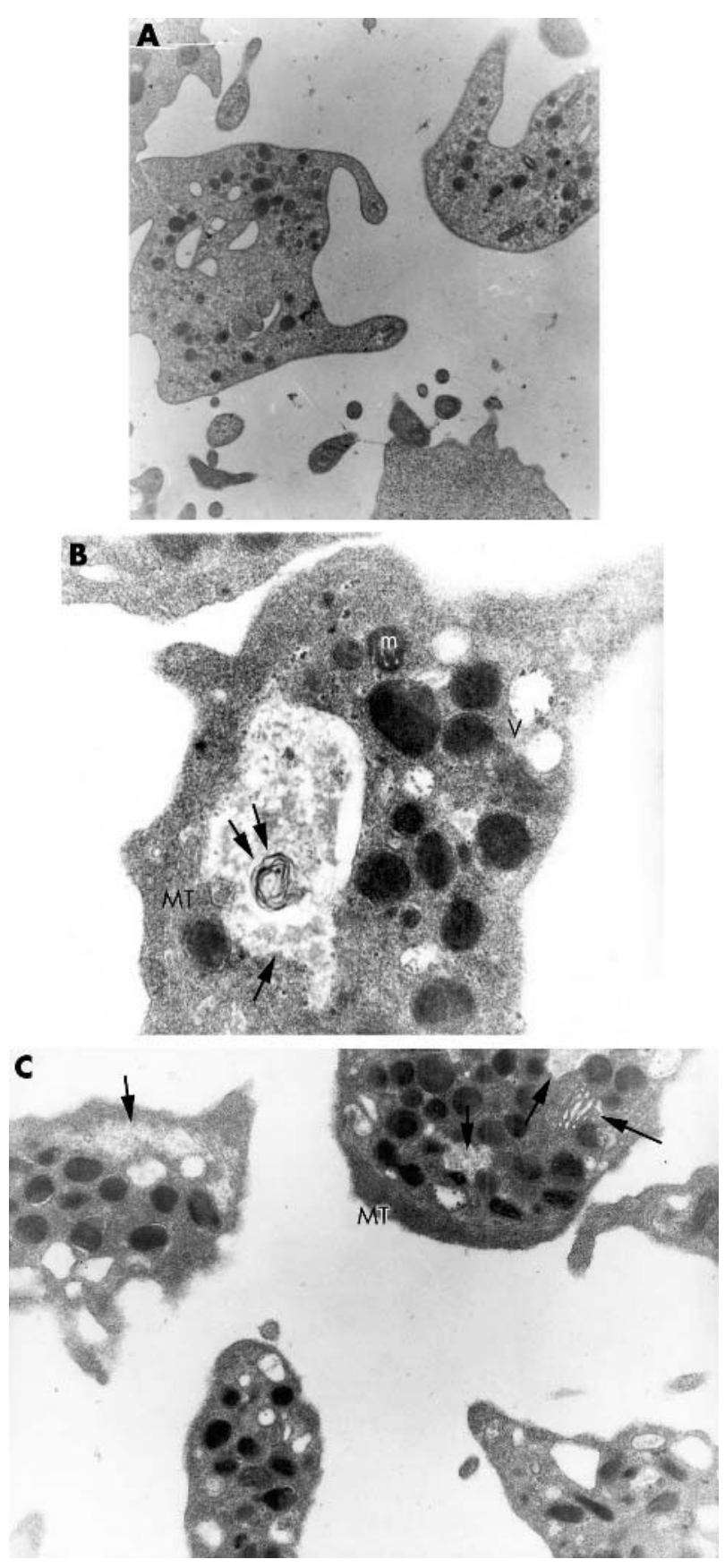

Figure 1 Transmission electron microscopy (TEM) images of platelets from (A) a normal control and $(B, C)$ patient 4 under TEM (original magnifications: $A, \times 12$ 930; $B, \times 27800 ; C, \times 12$ 930). The patient's platelets contained dense granules of different shapes and sizes $(B, C)$ and amorphous cytoplasmic inclusions (single arrow) with ( $B$, double arrow) and without ( $C$, single arrow) a myelin figure; an intact mitochondrion (m) and microtubuli (MT) are also seen. Vacuolar spaces (V) with amorphous electron dense material (B, C), a Golgi complex (arrow), and a platelet that is undergoing spontaneous release are striking (C).

remaining platelets, was aspirated and discarded and the last layer, which was just above the red blood cells and contained leucocytes, was transferred into another $10 \mathrm{ml}$ centrifuge tube. The platelets were washed and centrifuged twice at $1750 \times g$ for 10 minutes, and the final pellet was resuspended in $0.2 \mathrm{ml}$ of distilled water. The leucocyte layer was centrifuged at $1000 \times g$ for five minutes and the supernatant was discarded. The pellet was washed repeatedly with distilled water to haemolyse the red blood cells until a clear leucocyte solution was obtained. The clear leucocyte pellet was resuspended with $0.2 \mathrm{ml}$ distilled water. The final suspensions of platelets and leucocytes were sonicated on ice three times for 10 seconds, with cooling intervals of 10 seconds. The suspensions were centrifuged at $15000 \times g$ for 10 minutes. Protein concentrations in the supernatants were determined with microprotein- $\mathrm{PR}^{\mathrm{TM}}$ kit (Sigma) on a Hitachi P800 autoanalyser. Next, the supernatants were deproteinised by the addition of SERAPREP ${ }^{\mathrm{TM}}$ (Pickering Laboratories, Mountain View, California, USA) at a ratio of 1 to 1 , an internal standard was added (sarcosine, $10 \mu \mathrm{mol} /$ litre), and they were centrifuged for 10 minutes at $15000 \times \mathrm{g}$. Finally the cystine concentration of the supernatants was measured by ion exchange high performance liquid chromatography with post column derivatisation by ninhydrin (Series 1100 (Agilent Technologies, Palo Alto, California, USA) combined with PCX 3100 post-column reaction module (Pickering Laboratories).

\section{Statistics}

The Mann Whitney U test was performed for comparison of the mean granule number/platelet, the cystine concentrations within the platelets and leucocytes, and the different types of uranaffin granules in the patients compared with those of the control group.

\section{RESULTS}

Platelet and dense granule morphology evaluated by TEM

Dense granules varied in size and shape, with most being round and some being oval (control, fig lA; patients fig 1B, C). Some platelets showed features of immaturity, such as those from patient 4, which contained Golgi complex (fig lC). The platelets of all patients contained a bundle of microtubules around the periphery, which gave them their lenticular shape (fig 1B, C). There were many vacuolar spaces, which were composed of viscous, electron dense material (fig 2A). All of the patients' platelets contained heterogeneous cytoplasmic inclusions of various sizes, which were lamellous or amorphous in nature and were not encircled by a unit membrane (figs 1B, C, 2B). Myelin figures were seen in some of these inclusions (figs 1B, 2B). Interestingly, the same kind of cytoplasmic inclusion was also detected in the cytoplasm of a lymphocyte from patient 3 (fig 2C). Centrifugation caused spontaneous platelet release reactions (figs $1 \mathrm{C}, 2 \mathrm{~B}$ ) and the cytoplasmic inclusions were seen to be intact in those platelets during spontaneous release. The released material seen nearby the platelets had viscous, amorphous, and lamellary characteristics (fig $2 \mathrm{~B}$ ).

The uranaffin reaction on thin section electron microscopy was used to classify the dense granules into types 1-4. Mean (SD) values for the patients versus the controls were: type 1 granules in $40.31 \%(10.13 \%)$ versus $31.2 \% \quad(4.11 \%)$ $(\mathrm{p}=0.67)$; type 2 in $8.51 \%(1.95 \%)$ versus $17.22 \%(1.58 \%)$ $(\mathrm{p}=0.01)$; type 3 in $31.42 \%(8.45 \%)$ versus $37.98 \%(2.21 \%)$ $(\mathrm{p}=0.91)$; and type 4 in $19.73 \%(3.31 \%)$ versus $13.6 \%$ $(1.86 \%)(\mathrm{p}=0.11)$ of all DGs (fig 2D).

\section{DGs evaluated by fluorescence microscopy}

The mean (SD) number of fluorescent granules/platelet was $2.9(0.2)$ in the patients and $3.3(0.2)$ in the controls $(\mathrm{p}=0.34)$.

\section{Aggregation tests}

The bleeding time was prolonged in four of the seven patients. Primary or secondary aggregation defects were seen with $2 \mu \mathrm{M}$ ADP in five of the seven patients. By increasing the $\mathrm{ADP}$ dose to $10 \mu \mathrm{M}$ in four of these five patients, normal 

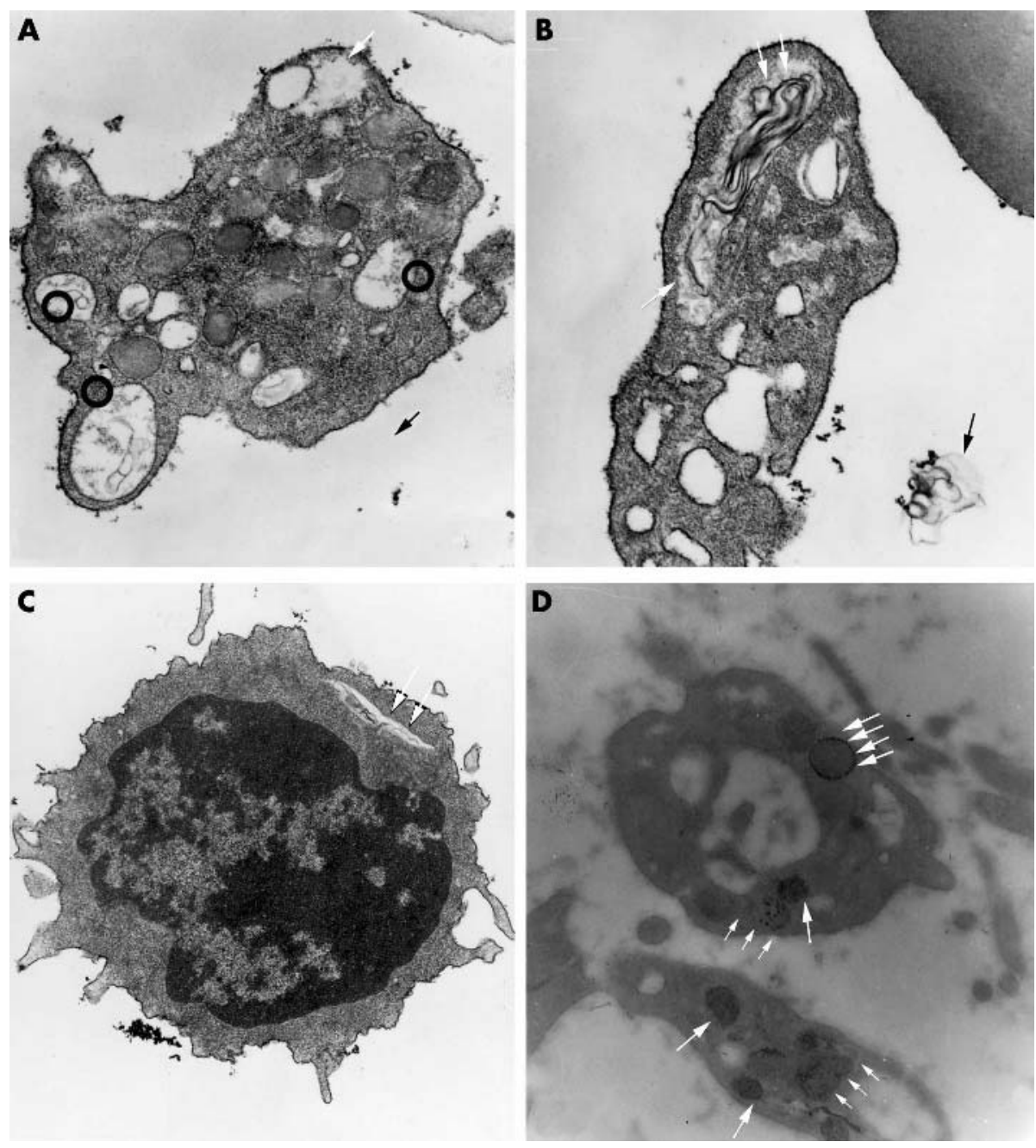

Figure 2 Transmission electron microscopy images of platelets from patients $5(A), 3(B)$, and $4(D)$ and a lymphocyte from patient 3 (C) loriginal magnifications: $A, \times 27800, B$, $\times 35$ 970; C $\times 12$ 930; D, $\times 27800$ ).

The enlarged open canalicular system (O), which is full of lamellary and amorphous material, and cytoplasmic amorphous inclusions (single arrow) can be seen in patient 5 (A). Lamellary cytoplasmic inclusions (single arrow) can be seen in the platelets of patient 3 (B). Longitudinal sections of myelin figures (double arrow) can be seen in the platelets (B) and a lymphocyte from the same patient $(C)$. The spontaneous release of a lamellary, viscous material is striking (thin arrow) (B). In the platelets that are undergoing spontaneous release, the cytoplasmic vacuoles and accumulations remain intact (B). Uranaffin staining of platelets from patient 4 revealed type 1 (one arrow) dense granules, which contained solid cores occupying more than $50 \%$ of the granule interior, type 3 (three arrows) granules with a fragmented core, and type 4 (four arrows) granules with no visible core (D). aggregation was attained in one, and minimal improvement was seen in the other three. Collagen $(2 \mu \mathrm{g} / \mathrm{ml})$ and epinephrine $(10 \mu \mathrm{M})$ induced platelet aggregation were found to be defective in one of the seven and three of the five patients studied, respectively. The absence of ATP release was confirmed by lumiaggregometry in two of three patients who had a platelet aggregation defect (table 1); minimal improvement was seen after increasing the ATP dose to $10 \mu \mathrm{M}$.

\section{TEM evaluation of platelet aggregation Second minute}

Although the platelets of patients 2, 3, 4, and 5 fitted together tightly and had abundant pseudopods, as in normal platelets, those of patient 1 were distant from each other and only a few displayed pseudopods, which were blunted. Whereas normal platelets should have released almost all of their granules by this time, degranulation was seen in almost none of the platelets from patients 1, 3, and 5 and only in a variable number of platelets from patients 2 and 4 . Granules were still dispersed throughout the platelet and execution (central clustering) was present in a few (patient 1) to a moderate number (patients 3 and 5) of platelets (fig 3).

Eighth minute

Whereas the platelets from patients 2 and 4 still fitted together tightly, as is normal, the interplatelet distance increased in patients 3 and 5 compared with the second minute. The platelets of patient 1 were still remote from each other. Although some (patients 2, 3, 4, and 5) still had pseudopods, the platelets from patient 1 had none. In patients 2 and 4, although degranulation took place in most of the platelets, a few still showed central clustering of granules. Platelets from patients 1, 3, and 5 showed different stages of transformation, some having completely or incompletely degranulated, yielding a enlarged open canalicular system, some still displaying central clustering of granules, and some having granules dispersed throughout (fig 3).

\section{4 th minute}

Although the platelets still fitted together tightly and displayed pseudopods in patients 2 and 4, as is normal, the interplatelet distance increased even more than at the eighth minute in patients 1,3 , and 5 . In patients 2 and 4 , central clustering of granules was not seen, and most of the platelets were degranulated and displayed an enlarged open canalicular system. In a few, granules persisted throughout the platelet, implying partial degranulation. Some platelets from patients 3 and 5 still displayed pseudopods and were still in different stages of transformation, with most showing granules dispersed throughout the platelet and some having partially or completely degranulated, yielding an enlarged open canalicular system to a varying extent. Pseudopods were lacking and granules were dispersed throughout most of the platelets in patient 1 . 

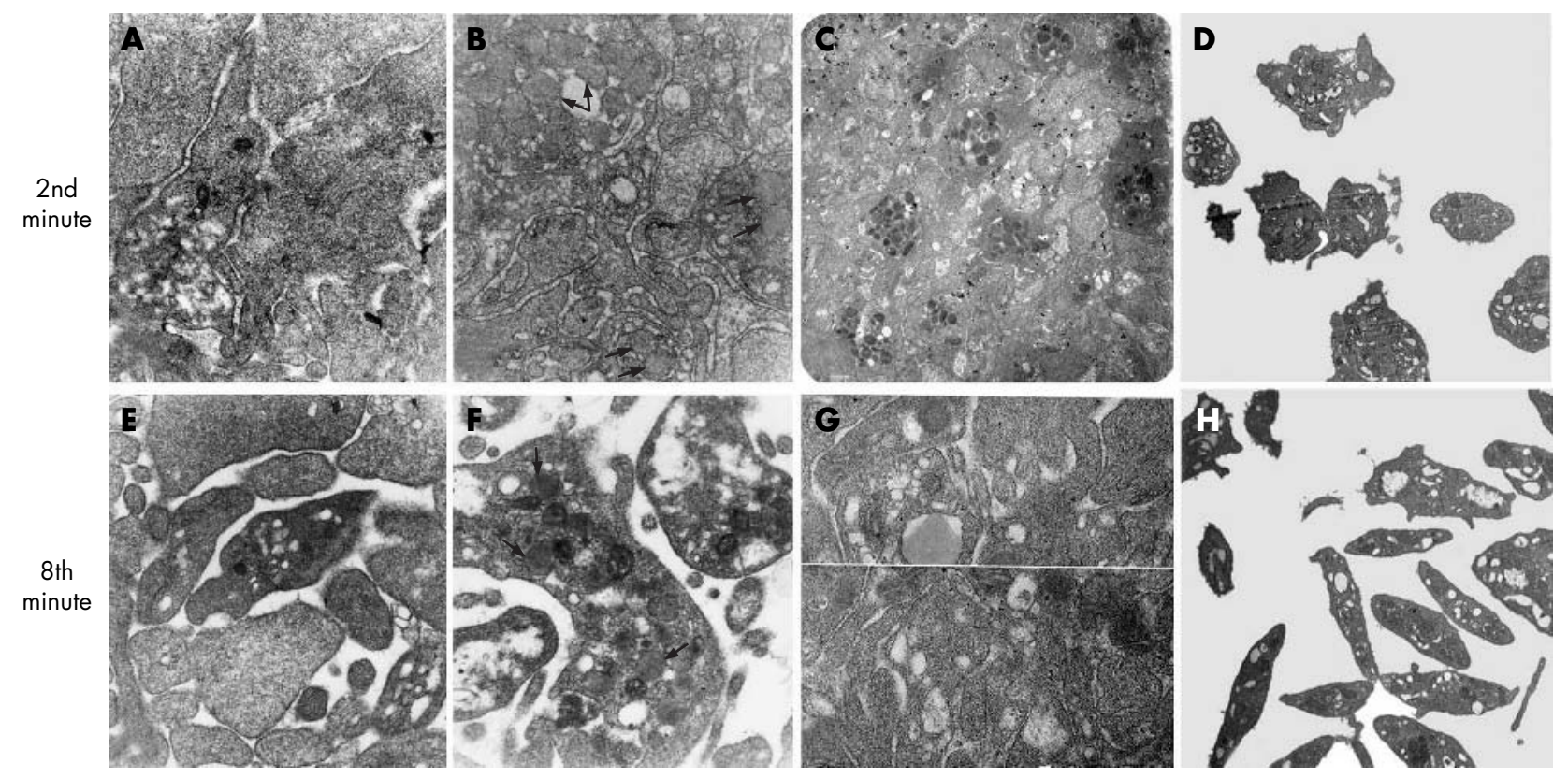

Figure 3 Transmission electron microscopy images of aggregating platelets during the second ( $A-D)$ and eighth minute ( $E-H)$ of $A D P$ stimulation from a control and patients 3,2 , and 1 , respectively (original magnifications: $A / B, \times 27800 ; C / D, \times 10000 ; E-G, \times 27800 ; H, \times 10000$ ). Second minute: although the control's platelets (A) and those of patients 3 (B) and 2 (C) fit tightly together and display abundant pseudopods, those from patient 1 (D) are distant from one another and only a few display pseudopods, which are blunted. Whereas normal platelets have released almost all of their granules (A), degranulation is seen in almost none of the platelets from patients 1 (D), a few platelets from patient 3 (B), and only in a moderate number of platelets from patient 2 (C). Granules are still dispersed throughout the platelet and central clustering is present in a few (patient $1 ; D$ ) to a moderate number (patient 3; B) of platelets. Eighth minute: whereas the control's platelets (E) and those of patient 2 (G) still fit tightly together, the interplatelet distance increased in patient 3 (F) compared with the second minute. The platelets from patient 1 (H) are still remote from each other. Although some (patients 2 and 3) still have pseudopods (F, G), the platelets from patient 1 have none (H). In patient 2, although degranulation has taken place in most of the platelets, a few still have granules. Platelets from patients 1 and $3(\mathrm{H}, \mathrm{F})$ show different stages of transformation: some have completely or incompletely degranulated, yielding an enlarged open canalicular system, and some have granules dispersed throughout.

\section{Evaluation of intraplatelet cystine concentrations}

The mean (SD) intraplatelet cystine concentration was higher in the patients than in the control group ( $1.56(0.84) v 0.08$ $(0.01) \mathrm{nmol} / \mathrm{mg}$ protein; $\mathrm{p}=0.008)$. The mean $(\mathrm{SD})$ cystine concentration within the leucocytes was also higher in the patients than in the controls $(8.64(3.81) v 0.11(0.01) \mathrm{nmol} /$ $\mathrm{mg}$ protein; $\mathrm{p}=0.008)$. The mean $(\mathrm{SD})$ protein content of the platelets $(164.4(81.8) \vee 407.4(72.2) \mathrm{mg} / \mathrm{dl} ; \mathrm{p}=0.08)$ and the leucocytes (126.2 (42.7) $v$ 165.4 (24.4) $\mathrm{mg} / \mathrm{dl}$; $\mathrm{p}=0.29$ ) was similar in the patients and the controls.

\section{Discussion}

In cystinosis, free cystine classically accumulates in the lysosomes, cytoplasm, nucleus, mitochondria, ${ }^{10}$ and the intracellular spaces of bone marrow in the form of characteristic crystals, granular, fine, dark material, or with no visible form in various cells. ${ }^{211}$

We showed that in NC cystine accumulates in platelets in neither the crystalline nor the darkened material form.

To our knowledge, intraplatelet accumulation of cystine has not been demonstrated before. In addition, intraplatelet cystine concentrations seen here may be lower than the pretreatment values because intraleucocyte values are reduced by treatment with cysteamine. ${ }^{12}$ Active pinocytosis and phagocytosis have been suggested to provide the mechanism for cystine accumulation, and this has been demonstrated in polymorphonuclear leucocytes and monocytes, but not in lymphocytes and erythrocytes. ${ }^{11}$ The relatively lower concentrations of cystine seen in platelets compared with leucocytes in our patients may reflect the fact that endocytosis and pinocytosis (which take place to supply some of the granule contents) are less active in megakaryocytes and platelets than in leucocytes.
It seems reasonable to assume that the lamellary and amorphous cytoplasmic inclusions in our patients are cystine accumulations. The existence of the same types of inclusions in the lymphocytes of patient 3 and their presence in all of the patients studied is striking. However, we did not investigate the presence of sulfur in these inclusions or in other parts of the platelets using electron probes, although we plan to do so in the near future.

It has been reported that vacuoles and vesicles are parts of the open canalicular system that have become dilated and are not characteristic for a particular disorder. ${ }^{13}{ }^{14}$ DGs in different stages of transformation ${ }^{15}$ and spontaneous platelet release caused by cytocentrifugation ${ }^{16}$ are seen normally. It is striking that the microtubule system is intact, giving the platelets their lens-like shape. Some of the platelets displayed features of immaturity, such as the presence of the Golgi complex seen in patient 4 , as seen in preleukaemia. ${ }^{17}$

The contrast between the morphological changes and the degree of cystine accumulation in our patients' platelets suggests that mechanisms other than cystine accumulation (which have not been identified yet) may be involved in the morphological and functional abnormalities of the platelets, as in the proximal tubuli. ${ }^{10}$

Among the seven patients, five had abnormal aggregation tests, four had a prolonged bleeding time (patients $1,3,5$, and 6) and only two (patients 1 and 6) had a bleeding tendency. These findings are similar to previous reports in that bleeding symptoms and/or abnormal laboratory tests (bleeding time and/or abnormal aggregation tests) are not present in all patients with platelet release defects, ${ }^{18-20}$ so that electron microscopic analysis is the most reliable tool for the diagnosis of platelet defects. ${ }^{20}$ Although CRF cannot be excluded as a cause of platelet dysfunction in patients 1 and 
6 , the prolonged bleeding time and/or abnormal platelet aggregation seen in the platelets of the patients $(2,3$, and 5$)$ who did not have CRF support the notion that cystinosis is a cause of platelet dysfunction. None of these patients took aspirin, non-steroidal anti-inflammatory drugs, or antihistamines for 10 days before the tests.

Because exogenous ADP is the main stimulator of DGs and to a less extent $\alpha$ granules, the lack of mainly secondary aggregation with ADP stimulation in our patients and the absence of grey platelets in light microscopic examination led us to distinguish between the two release defects involving DGs. ${ }^{18}$ The first is delta storage pool disease $(\delta$-SPD), in which the numbers of DGs are reduced but central clustering of the granules after stimulation take place normally, but temporarily, ${ }^{321}$ and the other is an aspirin-like defect in which granule numbers are normal but central clustering does not occur. ${ }^{21}$ This second defect may be hereditary ${ }^{18}$ or may be caused by the ingestion of aspirin and other drugs (anti-inflammatory agents, phenothiazines, antihistamines, tricyclic antidepressants), ${ }^{22}$ and the execution defect may be a component of aggregation defects in leukaemia ${ }^{23-25}$ and refractory anaemia. ${ }^{24}$

\section{"The aggregation pathology seen in our patients is similar to that seen in leukaemia and refractory anaemia, rather than an aspirin-like platelet defect, because it does not just involve the execution process but also induction and transmission"}

We first labelled the platelets with mepacrine, a fluorescent drug that selectively accumulates in platelet DGs, binding to serotonin or 5-hydroxytryptamine, and $\mathrm{ATP}^{3-5}$ to determine the number of DGs precisely, and demonstrated that the numbers of DGs were similar in patients and controls. Ultrastructural evaluation of DGs by the uranaffin reaction in which staining of DG membranes produces different staining patterns in normal and pathological conditions ${ }^{326} 27$ showed the predominance of full (type 1) DGs, unlike in $\delta$-SPD, in which the ADP and ATP content of the storage pool is lower than normal ${ }^{28} 29$ and empty (type 4 ) granules predominate. ${ }^{3}$ After confirming that the DGs of our patients had neither a quantitative nor morphological defect suggestive of $\delta$-SPD, we examined the ultrastructural changes that take place during aggregation, to determine whether a functional abnormality existed.

The ultrastructural platelet analysis of our patients revealed different degrees of abnormality at different stages of aggregation. For example, platelets from patients 2 and 4 showed that degranulation took place in most platelets later than in the controls, but a few incompletely degranulated platelets were left after 14 minutes. However, platelets from patients 1, 3, and 5 showed different stages of transformation, a lack or delay of central clustering of granules, and a moderate to high number of degranulated platelets. Adherence established at the second minute of aggregation was found to disappear at the eighth minute, implying intact primary but defective secondary aggregation in patients 3 and 5. The lack of evident shape change and few and blunt pseudopods, in addition to lack of platelet adherence, in patient 1 at the second minute of aggregation are consistent with a primary aggregation defect.

The aggregation pathology seen in our patients is similar to that seen in leukaemia and refractory anaemia, ${ }^{23-25}$ rather than an aspirin-like platelet defect, because it does not just involve the execution process (patients 1, 3, and 5) but also induction (patient 1) and transmission (patients 2, 4 mainly and 1,3 , and 5 ).

\section{Take home messages}

- As far as we are aware, this is the first study to demonstrate raised intraplatelet cystine concentrations, abnormal platelet ultrastructure, and an aggregation defect in nephropathic cystinosis (NC)

- Platelets should be added to the list of cells in which cystine accumulates and compromises cellular function, and cystinosis should be added to the disorders that give rise to platelet aggregation defects

- Patients with NC might be at increased risk for bleeding during surgical intervention or traumatic accidents, particularly if they have chronic renal failure

However, the aggravating effect of CRF on both adhesion and execution in patient 1 should also be taken into account.

The wide spectrum in the severity of defective aggregation may result from different mutations, which have yet to be defined, in the affected children.

Secretion depends upon active ATP production, ${ }^{30}$ and abnormal platelet aggregation has been reported in disorders with abnormal glucose metabolism. ${ }^{31}{ }^{32}$ The ADP/ATP content of DGs was reported to be both normal ${ }^{21} 28$ and low $^{23}$ in execution defects, including aspirin-like platelet defects. Subnormal degradation of metabolic ATP into its metabolites inosine monophosphate and hypoxanthine was reported in aggregation defects (including all phases of induction, transmission, and execution) in leukaemia, ${ }^{23}$ unlike $\delta$-SPD. ${ }^{33}$ We did not have the opportunity to measure ATP or its metabolites. However, the predominance of full DGs (type 1) in our patients, unlike that seen in $\delta$-SPD, and the low numbers of semi-empty DGs (type 2), seem to exclude insufficiency of adenine nucleotide content and impaired ATP transport across the granule membrane in platelets from our patients. ${ }^{3}$ In our patients' platelets, intracellular cystine accumulation may reduce ATP production by impairing oxidative phosphorylation, and may also reduce both intracellular phosphate and calcium concentrations, just as it does in the kidney cells of patients with NC. ${ }^{74}$ If this were the case, adequate messenger molecules would not be generated after interaction of agonists with their receptors, so that contractile mechanisms, centralisation of granules, and release would be partially or completely blocked.

The dilated open canalicular system seen in disorders with execution defects ${ }^{17} 2123$ may reflect ineffective reception and transmission of release inducing stimuli and thereby may impair the release mechanism more. Inadequate evacuation may be aggravated by the residual material, which may increase after each secretion attempt.

To our knowledge, this is the first report to demonstrate raised intraplatelet cystine, abnormal platelet ultrastructure, and an aggregation defect in NC. We suggest that platelets should be added to the list of cells in which cystine accumulates and compromises cellular function, and that cystinosis should be added to the disorders that give rise to aggregation defects involving mainly the transmission and execution phases. We think that patients with $\mathrm{NC}$, even if they have a normal bleeding screening assessment, might be at increased risk for bleeding during surgical intervention or traumatic accidents, particularly if they have CRF.

\section{ACKNOWLEDGEMENTS}

We are grateful to $\mathrm{H}$ Solmaz for his valuable technical assistance in the preparation of the ultrastructural samples, to Dr N Erarslan for her kind help in performing some aggregation tests, to Professor G Yıldırım for her helpful advice, to Drs A Can, A Olcay, and G Ersöz for their technical assistance in the preparation of the manuscript, and to 
our diligent nurse S Kıroğlu for drawing blood samples. This study was partially supported financially by the METVAK and DOKAV foundations.

\section{Authors' affiliations}

L Olcay, Section of Paediatric Haematology, Ankara Oncology Hospital, Demetevler, 06200, Ankara, Turkey

E Erdemli, Department of Histology-Embryology, Faculty of Medicine, Ankara University, 06100, Ankara, Turkey

M Kesimer, H S Kalkanoğlu, T Coșkun, Section of Nutrition and Metabolism, Department of Paediatrics, Faculty of Medicine, Hacettepe University, 06100, Ankara, Turkey

Y Büyükașı, Section of Haematology, Department of Internal Medicine, Faculty of Medicine, Hacettepe University

H Okur, C Altay, Section of Paediatric Haematology, Department of Paediatrics, Faculty of Medicine, Hacettepe University

\section{REFERENCES}

1 Gahl WA, Schneider JA, Aula PP. Lysosomal transport disorders: cystinosis and sialic acid storage disorders. In: Scriver CR, Beaudet AL, Sly WS, eds. The metabolic and molecular bases of inherited disease. New York: McGraw-Hill Inc, 1995:3763-97.

2 Gahl WA, Thoene JG, Schneider JA. Cystinosis. N Engl J Med 2002;347:111-21.

3 Weiss HJ, Lages B, Vicic W, et al. Heterogenous abnormalities of platele dense granule ultrastructure in 20 patients with congenial storage pool deficiency. Br J Haematol 1993;83:282-95.

4 Skaer RJ, Flemans RJ, McQuilkan S. Mepacrine stains the dense bodies of human platelets and not platelet lysosomes. Br J Haematol 1981;49:435-8.

5 Komarnicki M. Pietrzak I, Zozulinska M. Mepacrine-labeled platelet densebody number in patients with chronic uremia. Nephron 1988;50:306-7.

6 McNicol A. Platelet preparation and estimation of functional responses. In: Watson SP, Authi KS, eds. Platelets. A practical approach. Oxford: IRL Press, 1996: 1-26.

7 Dalton N. White cell cystine group: guideline no.1. Mixed leucocyte preparation. BIMDG bulletin, Spring 2001 (http://www.bimdg.org.uk/ bulletins/spring2001/WCYS_compiled.doc).

8 Chadefaux-Vekemans B. White cell cystine group: guideline no. 2 Polymorphonuclear leucocyte preparation. BIMDG bulletin, Spring 2001 (http://www.bimdg.org.uk/bulletins/spring2001/WCYS compiled.doc).

9 Spear GS, Slusser RJ, Tousimis AJ, et al. Cystinosis. An ultrastructural and electron-probe study of the kidney with unusual findings. Arch Pathol 1971;21:206-21

10 Gubler MC, Lacoste M, Sich M, et al. The pathology of the kidney in cystinosis. In: Broyer M, ed. Cystinosis. Amsterdam: Elsevier, 1999:42-8.

11 Schulman JD, Wong VG, Kuwabara T, et al. Intracellular cystine content of leukocyte populations in cystinosis. Arch Intern Med 1970;125:660-4.

12 Smolin LA, Clark KF, Schneider JA. An improved method for heterozygote detection of cystinosis, using polymorphonuclear leukocytes. Am J Hum Genet 1987;41:266-75

13 Maldonado JE. 'Swiss-cheese' platelets [letter]. Ann Intern Med 1974;81:860-1.

14 White JG. Interaction of membrane systems in blood platelets. Am J Pathol 1972;66:295-312.
15 White JG. Platelet morphology. In: Johnson SA, ed. The circulating platelet. New York: Academic Press, 1971:46-117.

16 Holmsen H. Platelet secretion. In: Colman RW, ed. Hemostasis and thrombosis: basic principles and clinical practice. Philadelphia: JB Lippincott Company, 1982:390-403.

17 Maldonado JE, Pierre RV. The platelets in preleukemia and myelomonocytic leukemia. Ultrastructural cytochemistry and cytogenetics. Mayo Clin Proc 1975:50:573-87.

18 Bick RL. Platelet function defects: a clinical review. Semin Thromb Hemost 1992; 18:167-85

19 Nieuwenhuis HK, Akkerman JW, Sixma JJ. Patients with a prolonged bleeding time and normal aggregation tests may have storage pool deficiency: studies on one hundred and six patients. Blood 1987;70:620-3.

20 Jasty R, Kuerbitz S, Matthew P. Correlation of clinical severity of bleeding with electron microscopy findings in a group of pediatric patients with platelet storage pool deficiencies at a single institution [abstract]. J Pediatr Hematol Oncol 2001;23:1146

21 Weiss HJ, Ames RP. Ultrastructural findings in storage pool disease in aspirinlike defects of platelets. Am J Pathol 1973;71:447-66.

22 Weiss HJ, Rogers J. Thrombocytopathia due to abnormalities in platelet release reaction-studies on six unrelated patients. Blood 1972;39:187-96.

23 Cowan DH, Graham RC, Baunach D. The platelet defect in leukemia. Platelet ultrastructure, adenine nucleotide metabolism, and the release reaction. J Clin Invest 1975:56:188-200.

24 Pintado T, Maldonado JE. Ultrastructure of platelet aggregation in refractory anemia and myelomonocytic leukemia. I. Ultrastructure of aggregation in normal controls and general defects in refractory anemia and myelomonocytic leukemia. Mayo Clin Proc 1976:51:379-92.

25 Cowan DH. Acquired disorders of platelet function. In: Colman RW, ed. Hemostasis and thrombosis: basic principles and clinical practice. Philadelphia: JB Lippincott Company, 1982:516-24.

26 Richards JG, Da Prada M. Uranaffin reaction: a new cytochemical technique for the localization of adenine nucleotides in organelles storing biogenic amines. J Histochem Cytochem 1977;25:1322-36.

27 Payne CM. A quantitative ultrastructural evaluation of the cell organelle specificity of the uranaffin reaction in normal human platelets. Am J Clin Pathol 1984:81:62-70.

28 Holmsen $\mathrm{H}$, Weiss HJ. Further evidence for a deficient storage pool of adenine nucleotides in platelets from some patients with thrombocytopathia-"storage pool disease". Blood 1972;39:197-209.

29 Lages B, Holmsen H, Weiss HJ, et al. Thrombin and ionophore A23187induced dense granule secretion in storage pool deficient platelets: evidence for impaired nucleotide storage as the primary dense granule defect. Blood 1983:61:154-62.

30 Holmsen H. Biochemistry of the platelet: energy metabolism. In: Colman RW, ed. Hemostasis and thrombosis: basic principles and clinical practice. Philadelphia: JB Lippincott Company, 1982:431-43.

31 Hutton RA, Macnab AJ, Rivers RPA. Defect of platelet function associated with chronic hypoglycaemia. Arch Dis Child 1976;51:49-55.

32 Ambruso DR, McCabe ERB, Anderson D, et al. Infectious and bleeding complications in patients with glycogenosis $\mathrm{lb}$. Am J Dis Child 1985; 139:691-7.

33 Holmsen $\mathrm{H}$, Weiss $\mathrm{HJ}$. Hereditary defect in the platelet release reaction caused by a deficiency in the storage pool of platelet adenine nucleotides. Br J Haematol 1970;19:643-9

34 Haq S, van't Hoff W. Cellular dysfunction in cystinosis. In: Broyer M, ed. Cystinosis. Amsterdam: Elsevier, 1999:14-19. 